This is an Accepted Manuscript of an article published by Taylor \& Francis in Information Society on $15^{\text {th }}$ of March 2017, available online:

\title{
http://www.tandfonline.com/doi/abs/10.1080/01972243.2016.1271070
}

A limited number of free copies of the article are available here:

http://www.tandfonline.com/eprint/JBmBwwKgCe3XCj9ektTd/full

\section{Being old in an always-on culture: Older people's perceptions and experiences of online communication}

Marika Lüders, Department of Media and Communication, University of Oslo, Oslo, Norway

Edith Roth Gjevjon, Department of Master Education, Diakonova University College, Oslo, Norway. Department of Nursing Science, University of Oslo, Oslo, Norway

\section{CONTACT INFORMATION}

Marika Lüders, Department of media and communication, P.O.box 1093 Blindern, 0317 Oslo, Norway, EMAIL: marika.luders@media.uio.no

\begin{abstract}
Research on the digital divide has moved beyond connectivity to skills and usage disparities. Yet for many older people lack of connectivity remains a challenge, and for those who do have access skills and usage remains an issue. We report findings of an in-depth qualitative study of older people's perceptions of online communications and also their actual experiences. Findings indicate that older people who are already socially well connected benefit from online communication more than those who are not.
\end{abstract}

\section{Key words}

Older people, elderly, digital divide, online communication, Facebook, quality of life, social relations. 


\section{Introduction}

Use of online forms of communication, such as e-mail, messaging apps (e.g. iMessage, Snapchat, WhatsApp), Voice over IP systems (e.g. Skype, Facetime, Google Talk), and social network sites (SNSs) is significantly lower among people over 65 compared to younger age groups (Duggan 2015; Vaage 2015). While there has been a steady increase in number of older people using the Internet, smartphones and tablets, the disparities vis-à-vis the younger age-groups remain significant. In UK $52 \%$ of people 65 years and older go online, compared to $86 \%$ for all age-groups, and $93-98 \%$ for those in the 16-54 age group. The corresponding figures for smartphone ownership are $17 \%, 66 \%$, and $74-88 \%$ (Ofcom 2015). In Norway, where our study was conducted, the uptake of Internet and Internet-enabled technology is higher: $54 \%$ of people in the $67-79$ age group report Internet use on an average day, compared to $88 \%$ for all age-groups, and $86 \%-97 \%$ for the $16-66$ age group. The figures for smartphone ownership for the first two age-groups are $31 \%$ and $80 \%$ and for the $9-66$ age-group it is $75-97 \%$ (Vaage 2015).

As online and offline social spheres of life get increasingly enmeshed, there is increasing risk of older people feeling socially excluded and also actually getting excluded. On the other hand, social life is crucial for their social, physical and mental well-being (Ala-Mutka et al. 2008, WHO 2002). We examine older people's perceptions of online communications and also their actual experiences to understand how communication technologies can be used to enhance their social participation and thereby their quality of life.

The rest of the paper proceeds as follows. The next two sections discuss the existing research on the relationship between social relations and active aging and the role mediated communications can play. The subsequent sections present the research questions, methodolgy, and findings. The last section offers concluding thoughts.

\section{Social relations, active ageing and quality of life}

Quality of life (QoL) has been shown to be consistently associated with active ageing (Bowling 2009). QoL is influenced by objective, subjective, societal and individual factors and interactions between them (Walker and Mollenkopf 2007). What is noteworthy for our purposes is that Farquhar (1995) found that family relationships and social contacts and activities were as valued QoL-components as general health and functional status by older people.

Social support is one of the enablers of active ageing, as social connections and intimate relationships are sources of emotional strength (WHO 2002). While social networks grow smaller with age, older people have a greater need for well-acquainted social partners (Ashida and Heaney 2008; English and Carstensen 2014). As people approach the end of life, they care more about 
meaningful social ties (Carstensen et al. 2003). At the same time, while acknowledging the social significance of close-knit networks among older people, Cornwell (2011) argues that it is important for older people to also maintain social links, as they support autonomy. Thus one might expect that a combination of stronger and weaker social ties would help the older people through their advancing years.

The hard reality is that with advancing age it becomes difficult for older people to maintain both strong and weak social ties. On the one hand, there are relationship losses due to death, poor health, and residential relocation of friends and family. On the other hand, opportunities for socializing get restricted with decline in older adults' own health and mobility (Liu and Rook 2013; Honigh-de Vlaming et al. 2014; Savikko et al. 2005). Such factors often start a downward spiral, wherein reduced social networks and loneliness leads to reduced energy and motivation (Hauge and Kirkevold 2012) and decline in health (Cornwall and Waite, 2009; Coyle and Dugan 2012) and that in turns leads to further constriction of social connections.

\section{The social significance of mediated communication}

Before discussing online communication, we briefly examine the social value of pre-digital forms of communication. Both letters and the telephone are used to maintain relationships at a distance (Cathcart and Gumpert 1986; Peters 1999; Aronson [1971] 1986; Fischer 1992). Aronson ([1971] 1986) highlights the importance of the telephone as one of several integrating tools in the emergent modern mass society. More precisely, the telephone supported dispersed social networks, as people were increasingly able to develop and maintain social relationships in societies characterised by physical distances between family members and between close friends (Aronson [1971] 1986). Communication at a distance, regardless of format, is as such "an expression of desire for the presence of the absent other" (Peters 1999, p. 180).

Today's older people in Western countries were the first "phone generation", who experienced the adoption and domestication of the home telephone. The phone has become integrated into patterns of social contact (Haddon and Silverstone 1996). It serves as a means of insuring the safety and emotional security of older people (Aronson [1971] 1986). It supports the social life of older people, particuarly those who have lost their spouses (Utz et al. 2002). It is the primary channel for keeping in touch with family and social relations (Ling 2008). While the the mobile phone has become an increasingly important tool connecting older people with family and friends, the adoption of the mobile phone among older people has been slower compared to younger age-groups (Ling 2008).

At the turn of the century, Selwyn (2004) found that older people typically regarded the Internet as a functional tool rather than as a tool for social interaction and participation. Nowadays, older people 
do increasingly connect online for social purposes. For instance, in the US $48 \%$ of Internet users age 65 or older use Facebook (Duggan 2015). Yet the full potential of online interaction and support among older people has not been realized.

The "rich get richer" model predicts that the social benefits of Internet-use are stronger and more prevalent for people who already have social support (Kraut et al. 2002). In the case of older people, that would mean that those with already stronger social networks will benefit more from Internet access and use than those with weaker ones. Prior studies on younger age-groups support the "rich get richer" model (Brandtzæg 2012; Kraut et al. 2002; Valkenburg and Peter 2009). On the other hand, other studies point to how introverted people, people with smaller social networks, and people with low self-esteem may prefer and benefit from the more protected and editable social environments online (Steinfield et al. 2008; Valkenburg and Peter 2009).

Experimental research, examining user-experiences of tailor-made systems for older people has been conducted: the touch-device "Building Bridges" system was designed as a simple interface for broadcast, chat, group-chat, calls and messaging, enabling older people to connect with family and friends as well as meeting new people (Garattini et al. 2012). With regard to new weak tie connections, the pilot-users of the "Building Bridges" system gradually experienced the need to share more personal information than the system enabled, and they emphasized the importance of linking online interactions with face-to-face meetings. These findings can be interpreted as an urge to turn weak ties into stronger ties. Efforts have also been made to integrate knowledge from the gerontology literature and Human-Computer Interaction, with the aim of identifying themes with implications for how technology might support social connections for older people (Lindley et al. 2008): Older people prioritize close and emotionally meaningful ties, and hence prefer technologies that support these close ties. Lindley et al. (2008) also emphasize the importance of solutions that enable families to show their care without intruding or compromising the autonomy of older people. In terms of family relationships, older people might be more inclined to value technologies that enable them to keep track of the everyday lives of their offspring rather than having their own lives monitored.

Given the widespread adoption of SNSs, many studies have been conducted on older people's use and lack of use of these services, typically finding that older people have privacy concerns and problems with grasping the purpose, usefullness, and value of such services (Braun 2013; Chung et al. 2010; Gibson et al. 2010; Xie et al. 2012; Lehtinen et al. 2009; Lüders and Brandtzæg 2017; Nef et al. 2013). 
Studies on assocations between SNS-use and social capital among people in other age-groups suggest that these technologies have the potential for providing older people easy means of staying in touch with family, friends and social contacts. These studies show that SNSs help in maintaining an extended social network, and participating in SNS-mediated social exchanges is associated with increases in bridging social capital (Brandtzæg 2012; Burke, Kraut, and Marlow 2011; Ellison et al. 2014; Steinfield et al. 2008). Brandtzæg (2012) also found SNS-users to report significantly more face-to-face interactions with close friends, which points towards a positive association between SNS-usage and bonding social capital. Here it needs to be noted that close friends typically communicate over many channels, including face-to-face (Haythornthwaite 2002). Hence, whereas close friends might very well communicate extensively via SNSs, their relationships are not dependent on these services in the same way as for weak ties.

For the adoption of communication technologies by older people, close friends and relatives are important also as "warm experts", that is, people who are present in the technology non-user's or novice's lifeworld, and who have the knowledge and skills to use the technology and are willing to help and teach (Bakardjieva 2005, p. 99). With regard to both adult and older people new to computers and the Internet, Bakardjieva found warm experts to play a crucial role in mediating between the technology and the situation and needs of novice users. This adds even more significance to the importance of close friends and relatives for older users. Older people tend to priortize strong ties, and among these strong ties, they may also find the support they need to adopt networked devices and services.

Finally, we need to consider the potentially unfortunate social consequences of being always-on, with smartphones interrupting social settings. With networked, handheld devices, the distinction between online and offline "stabilizes into a sense of continual co-presence", and we become tethered to our always-on/always-on-us devices, or rather the people, services and services we reach through them. (Turkle 2008, p. 122). As a consequence we are always potentially distant even when situated in physical here and now settings. In Turkle's (2011) account, the always-on culture distances us from each other; we end up fearing the intimacy of being together, and prefer the the continual yet flat connections enabled by technology. Turkle's work alerts us to the potential downside of connectvity, which we need to be mindful of.

\section{Research questions}

Given the increasing importance of mediated sociability in today's society, there is a need to better understand how older people perceive and experience mediated communication. To that end, we pursue the following research questions: 
How do older people perceive the always-on culture?

Do they feel left out?

How do older people describe the potential value of online communication for maintaining the social contacts important for them?

How do older people describe the experience of online communication for maintaining the social contacts important for them?

How do these depictions vary with the social context of the older people?

\section{Method}

\section{Research design}

A qualitative and explorative intervention study was conducted from August 2013 to May 2015 with 24 people, aged 60-95 (average age: 76), who at the beginning of the study had little or no experience with ICT. Participants were recruited in four municipalities (population between 30,000 and 114,000), located between 20 and $40 \mathrm{~km}$ from Oslo. Following Orimo et al. (2006), we focused on recruiting participants 65 years and older living in a residential care facility or at home. Two participants were about 60 years old: one lived in a residential care facility for older people, and one lived at home. Both received similar care services as the older participants. Thirteen participants were female, and 11 were male.

Participants were provided tablets (iPads), which they kept after the study, because it is easier to learn to use a touchscreen tablet than a PC (Caprani et al. 2012; Findlater et al. 2013). They were also provided regular one-to-one support from researchers and volunteers. In two of the municipalities, volunteers were youth. In each municipality a researcher, who was assisted by volunteers, introduced the iPads to the participants and guided them through written instructions. Regular meetings between the participants, the volunteers and the researcher were held on average once a month over a period of 12 months in each municipality. The intervention with the introduction of the iPads and meetings with volunteers and researchers was explorative and largely focused on the preferences of the participants. Their interests and curiosity steered their adoption of Internet-based applications.

\section{Data collection and analysis}

Participants were interviewed face-to-face two and three times each. The interviews were conducted prior to the introduction of the iPad, about half way in the process, and after completion. 
One participant died during the project, and two participants quit after short time due to illness and lack of interest. These participants were interviewed only once. All interviews were recorded and transcribed verbatim. The participants are anonymized and pseudonyms and approximate age are used in the analysis.

We used NVivo 10 to code the interviews. In accordance with thematic analysis approach, all interviews were coded inductively and coding categories were identified from the interview data. We used open coding to assign initial codes through close examination and exploration of the data. As the analysis progressed, we developed a consensus on the properties of the codes. Lastly, we analysed how the themes that emerged through our coding and analysis fit with pre-existing theory and the extant literature.

\section{Findings}

In the analysis we first discuss how the older participants depict the always-on culture as excluding. In the second part of the analysis, we discuss how the participants as digital novices assess the social value of online communication. Table 1 provides an overview of the participants' social and work lives before the project. Work-life is categorized according to the International Standard Classification of Occupations ${ }^{1}$.

\begin{tabular}{|c|c|c|c|}
\hline $\begin{array}{l}\text { Social life } \\
\text { before project }\end{array}$ & Participants & Earlier work-life & Close family and friends before project \\
\hline \multirow[t]{4}{*}{$\begin{array}{l}\text { Limited social } \\
\text { life }\end{array}$} & Ruth95 & Service worker & $\begin{array}{l}\text { Widow. No children. Weekly visits by } \\
\text { brother. Few friends. }\end{array}$ \\
\hline & Ingrid75 & Clerk & $\begin{array}{l}\text { Widow. } 1 \text { daughter. Very little family. } \\
\text { Feels alone. }\end{array}$ \\
\hline & Jon90 & Craftsman & $\begin{array}{l}\text { Single. No children. Keeps in touch with } \\
\text { sister and niece. }\end{array}$ \\
\hline & Karl70 & Craftsman & $\begin{array}{l}\text { Widower. } 1 \text { daughter, } 3 \text { grand-children. } \\
1 \text { sister. Feels alone. }\end{array}$ \\
\hline \multirow[t]{7}{*}{ Mostly family } & Hans80 & Craftsman/transport & $\begin{array}{l}\text { Married with Marie70. } 1 \text { daughter. } 5 \\
\text { siblings. A few friends left. }\end{array}$ \\
\hline & Irene65 & Ass. professional & $\begin{array}{l}\text { Divorced. } 3 \text { children and grand- } \\
\text { children. } 1 \text { friend. }\end{array}$ \\
\hline & Solveig90 & Service worker & $\begin{array}{l}\text { Widow. } 3 \text { children and grand-children } \\
\text { near-by. }\end{array}$ \\
\hline & Lisa90 & Service worker & $\begin{array}{l}\text { Widow. } 2 \text { daughters, } 4 \text { grandchildren. } \\
\text { Visits weekly. } 2 \text { friends. }\end{array}$ \\
\hline & Per65 & Business professional & $\begin{array}{l}\text { Married. } 1 \text { daughter, } 2 \text { grand-children } \\
\text { close-by. A few friends. }\end{array}$ \\
\hline & Arne90 & Manager, retail & $\begin{array}{l}\text { Widower. Very big family visits often. } 2 \\
\text { friends left. }\end{array}$ \\
\hline & Astrid85 & Self-employed & Widow. 2 children, 2 grand-children. \\
\hline
\end{tabular}




\begin{tabular}{|c|c|c|c|}
\hline & \multirow{3}{*}{$\begin{array}{l}\text { Mary80 } \\
\text { Kristian85 }\end{array}$} & \multirow{3}{*}{$\begin{array}{l}\text { Clerk } \\
\text { Graduate engineer }\end{array}$} & \multirow[b]{2}{*}{$\begin{array}{l}\text { Very close. A few friends. } \\
1 \text { daughter, } 2 \text { grand-children. Weekly } \\
\text { visits. }\end{array}$} \\
\hline & & & \\
\hline & & & $\begin{array}{l}\text { Widower. } 1 \text { son, } 1 \text { daughter, grand- } \\
\text { children. Weekly visits. }\end{array}$ \\
\hline & Morten75 & Graduate engineer & $\begin{array}{l}\text { Divorced. } 2 \text { children, } 4 \text { grand-children. } \\
\text { Visits regularly. } 1 \text { friend. }\end{array}$ \\
\hline & Tor60 & Transport & $\begin{array}{l}\text { Married. } 2 \text { children and } 4 \text { grand- } \\
\text { children near-by. }\end{array}$ \\
\hline & Jenny85 & Gardener & $\begin{array}{l}\text { Widow. } 3 \text { daughters, } 8 \text { grand-children. } \\
\text { Visits daily. } 1 \text { friend. }\end{array}$ \\
\hline \multirow[t]{8}{*}{$\begin{array}{l}\text { Family and } \\
\text { friends }\end{array}$} & Olav60 & Transport & $\begin{array}{l}\text { Divorced. } 2 \text { children, } 2 \text { grand-children. } \\
\text { Visits. Several friends. }\end{array}$ \\
\hline & Anne80 & Service worker & $\begin{array}{l}\text { Widow. } 2 \text { daughters, } 6 \text { grand-children. } \\
\text { Visits. Several friends. }\end{array}$ \\
\hline & Marie70 & Clerk & $\begin{array}{l}\text { Married with Hans80. } 1 \text { daughter. } 2 \\
\text { sisters. Several friends. }\end{array}$ \\
\hline & Heidi65 & Clerk & $\begin{array}{l}\text { Married } 2 \text { children, } 4 \text { grand-children. } \\
\text { Several friends, social. }\end{array}$ \\
\hline & Inger75 & Service worker & $\begin{array}{l}\text { Widow. } 6 \text { children, } 11 \text { grand-children. } \\
\text { Visits regularly. }\end{array}$ \\
\hline & Johan65 & Transport & $\begin{array}{l}\text { Married. } 1 \text { daughter, } 2 \text { grand-children } \\
\text { near-by. Several friends. }\end{array}$ \\
\hline & Nina65 & Service worker & $\begin{array}{l}\text { Married. } 2 \text { children, } 4 \text { grand-children, } \\
\text { near-by. Several friends. }\end{array}$ \\
\hline & Harald65 & Craftsman & $\begin{array}{l}\text { Married. } 2 \text { children, } 4 \text { grand-children, } \\
\text { near-by. Several friends. }\end{array}$ \\
\hline
\end{tabular}

Table 1: Overview of participants, earlier work-life and most important social relationships

\section{The always-on culture}

With the widespread adoption and use of smartphones, those without them are now witnessing friends, care-takers and family occupied with an online world that is always there, present as a more or less opaque window to a sphere of life they cannot see through. Rather than addressing reasons and barriers for non-use (see e.g. Selwyn 2004; Braun 2013; Xie et al. 2012; Hakkarainen 2012), we examine how older people describe the always-on culture from their vantage-point as outsiders. This part of the analysis is based on the data from the first round of interviews.

Our findings point to the matter of fact way in which they see the hyperconnected society as being here for better or worse, with or without them. Nostalgia about old days, where drop-in visits were common, and where people focused on the here and now of social meetings is prevalent, yet they do not dwell on stories of what used to be.

When they describe their experiences of being situated outside, three types of depictions are common. The first centres on how small children seem to be capable of using tools that for the older people are still unfamiliar; the second concerns the puzzlement with how smartphones and tablets 
can really contain "everything"; and the third is a reconciled sigh with how these networked devices frequently interfere with the here and now of social situations.

If kids can, so can I? Observations that small children appear naturally part of, and more or less born into, an always-on culture prompt two different feelings. Seeing kids with tablets and smartphones increases a feeling of being outside, but it also raises curiosity about how low a threshold these handheld devices have for use.

Nowadays two and three year old kids get these small TVs, or computers, no I mean phones (Anne80).

You know, we're born 50 years too early. Those who are born these days have this extra thing in their head. Yes, because you know, when you see three year olds with tablets, you resign. It's like bam, it's so simple (Ingrid75).

Such observations prompt a desire to learn more, as the tablets and smartphones appear to have lowered the threshold for learning. If kids use these devices, so can they?

Puzzled and curious. The second depiction centres on bafflement with how handheld devices can really be used for anything, anytime. Research on user-acceptance of ICT among older people emphasizes how older people refrain from using ICT because they do not see the use-value or purpose as present or relevant (see e.g. Chung et al. 2010; Hakkarainen 2012). The usefulness and value of having access to small devices where you can access any kind of service is beginning to become apparent, coupled with inquisitiveness with how these small devices can contain what seems like the whole world.

No, like I see my grandson, he has one, and his daughter is even worse. She can do anything, even if she's not that old. But he has a small phone. And there he has everything, yesterday he looked up who different managers were married to and stuff. Yes, on his phone and with photos and all. He has music there also. I don't understand how it's possible to get all that stuff on a small phone. But this is what the world has come to (Kristian85).

The study participants point to how everything seems to be possible with handheld devices: paying your bills, ordering tickets, booking travels, listening to the whole world of music, reading newspapers, watching TVs, reading books, taking photos, staying in touch with geographically distant friends and family, all the things most of us take for granted. Not being part of that culture connects with an increasing awareness of not being fully included. 
It has, many many times, occurred to me that I don't know how to use these things. I have never been that interested. But yes, perhaps you do feel slightly left out (Hans80).

Before the spread of handheld devices, the networked culture was experienced as more distant. The experience of being left out increases when the always-on culture is integrated into all social and societal realms. Digitally excluded see surrounding people gazing into phones, and little by little they learn, second-hand, that their capabilities can be employed for needs that the older people also have. With this understanding, the study participants' motivation to become part of the digital world increases.

Social interference and exclusion. With regard to the third depiction, how networked devices often interfere with the here and now of social situations, the participants express some frustration, but typically coupled with an acceptance that this is the way life has become.

My daughter is the worst. She sits there with Facebook. That's where she is. Talked with her aunt, what she writes on Facebook, like 'now auntie wrote about what she had for dinner', my daughter is on Facebook continuously. Yet she still gets crazy when her son is there if he's there for too long (Johan65).

Johan65 lives close to his daughter's family, and they visit each other on a weekly basis. This also means he is not too annoyed when his daughter and grandchildren let their phones interfere with the visits. He does not expect all the time they spend together to be filled with heart-to-heart conversations. It is also worth noticing that his daughter shares family-related updates with him. Mary80 also gets weekly visits from her grand-children, though for her, the feeling that the phone interrupts with the visits is starker:

Mary80: But like, I notice when she [grand-daughter] sits there and uses her phone when she's here with me. Yes, and I have to like ask if maybe we should talk together or something. It happens.

Interviewer: Because she gets messages or?

Mary80: Yes, something. Probably something like that, there are sounds beeping and stuff. And she has to answer, right. Yes of course, she should be allowed to do that, but...

Turkle (2011) discusses how mobile technologies have made us "pausable", and how turning away from those in front of us to attend to our phones has become close to a social norm. In our study we see how these emerging social norms, common among younger generations, are experienced by older people. The mobile-phone becomes a social problem if it experienced as replacing the here and now of a visit, and leads to a feeling of being left out and socially demoted. This feeling is 
particularly stinging if visits are rare. This is something the older people seem to share and sympathize with each other. The following story by Anne80 is telling:

One of my friends had a visit by her two grandchildren, and they sat there with their phones. And she told them that sorry to say, but you are not here with your granny that often and for you to be so occupied with your phones, now put them away, sit here with me and talk. This time when you're actually here. And they put their phones away, and they talked together. And her grandson said it had been really very nice (Anne80).

Although the experience of being left-out seems to intensify with the widespread presence of connected handheld devices, the greater willingness to adopt these devices also means our participants have come closer to an always-on culture. They believe the threshold for learning to use handheld devices is lower, and they see how they too might need to become digitally included - for easier access to information and entertainment, and for maintaining relationships they value.

\section{Potential for enriching and extending social life through online communication}

The social networks of our participants (see Table 1) align with previous research: older people have relatively small social networks (Carstensen et al. 2003). Table 1 only includes information about close family and friends. In addition, the participants report that they meet peers at senior citizen's community centres or other organized activities, though these activities rarely lead to the formation of new close ties. Most participants describe how staying in touch and maintaining close relationships is what matters most to them, with family relationships being particularly important. While shrinking of social networks is regarded as an inevitable fact of becoming older, it still leaves empty spaces, and for some leads to loneliness. This is in line with research which shows that loneliness is a subjective experience with negative consequences that arises when social networks do not match the networks one would like to have (Dykstra 2009). In order to understand their assessment of the potential social value of online communication, we need to benchmark typical social challenges they experience.

Capacity for sociality. With older age, friends die or their mental health declines to the extent that socializing becomes less rewarding.

Interviewer: Do you have any friends that you still keep in touch with?

No, no, they are gone you know. We have one couple left, but they are so, or we used to play cards, but it doesn't work any longer. You need to play against people who can still remember at least a little (Astrid85, interview 1). 
Socioemotional selectivity theory posits that as people age, they focus on the present as opposed to the future, and they care more about experiencing meaningful social ties (Carstensen et al. 2003). Put bluntly, and as indicated by Astrid85, spending time with friends with decreasing mental health, might not be experienced as optimizing the quality of one's social life. The above quote should not be interpreted as a lack of care and love, as it points to how previously meaningful social activities lose their meaning.

Most of our participants talk almost prosaically about friends passing away, and social networks decreasing. With the closest ties, and particularly spouses, poor health and illnesses cause anxiety and act as reminders for the frailty of social connections with older age. Actual losses as well as the potential of future losses can be dire. Karl70 lives at a residential care facility, and hardly has any contact beyond occasional meetings with a couple of his peers at the facility. He has a sister and a married daughter with three children, yet meets them rarely. He still misses his late wife, and when asked whether there's anyone he would like to stay in touch with, he answers:

Karl70: That would have to be my wife, but she's... It's futile.

Interviewer: Did she pass away a long time ago?

Karl70: Yes. And I still miss her.

Interviewer: You used to go for walks with a friend?

Karl70: He died you see. Yes, and therefore I don't dare to get attached to people (Interview 1).

The participants in this study represent a range of experiences and situations, with older people who are quite content with their social life; via older people who are happy with the size and composition of their social networks, yet who experience that decreased physical health makes social gatherings exhausting; to older people who explicitly state that they are lonely. These different experiences also affect how they perceive digital means of staying in touch to be potentially rewarding.

The perceived and experienced value of mediated communication. Table 2 summarizes the outcomes of the intervention; whether and how the participants now use e-mail, iMessage, Skype and Facebook, and with whom they communicate.

\begin{tabular}{|c|c|c|c|c|}
\hline Online services & Participant & $\begin{array}{l}\text { Social life before } \\
\text { project }\end{array}$ & $\begin{array}{l}\text { Previous work- } \\
\text { life }\end{array}$ & Details on use/non-use \\
\hline \multirow[t]{5}{*}{$\begin{array}{l}\text { No or very little } \\
\text { use of online } \\
\text { communication }\end{array}$} & Ruth95 & Limited social life & Service-worker & $\begin{array}{l}\text { Explains e-mail is difficult to use, } \\
\text { and she does not know who to } \\
\text { contact. }\end{array}$ \\
\hline & Ingrid75 & Limited social life & Clerk & $\begin{array}{l}\text { Initially interested in Skype. Died } \\
\text { during the project. }\end{array}$ \\
\hline & Karl70 & Limited social life & Craftsman & $\begin{array}{l}\text { Tried Skype with his sister, but } \\
\text { found it too difficult. }\end{array}$ \\
\hline & Arne90 & Mostly family & Manager, retail & Very briefly tried e-mail. \\
\hline & Astrid85 & Mostly family & Self-employed & Quit after short period due to \\
\hline
\end{tabular}




\begin{tabular}{|c|c|c|c|c|}
\hline & & & & \\
\hline & Solveig90 & Mostly family & Service worker & $\begin{array}{l}\text { Illness. } \\
\text { Quit after } 2 \text { weeks due to lack of } \\
\text { interest. }\end{array}$ \\
\hline & Hans80 & Mostly family & $\begin{array}{l}\text { Craftsman/tran } \\
\text { sport }\end{array}$ & $\begin{array}{l}\text { No use of e-mail, Skype or } \\
\text { Facebook due to privacy issues. }\end{array}$ \\
\hline & Marie70 & Family and friends & Clerk & $\begin{array}{l}\text { Interested in e-mail, but husband } \\
\text { (Hans80) is very negative. }\end{array}$ \\
\hline & Anne80 & Family and friends & Service worker & $\begin{array}{l}\text { Finds e-mail and Facebook too } \\
\text { difficult. }\end{array}$ \\
\hline \multirow{9}{*}{$\begin{array}{l}\text { Skype, } \\
\text { iMessage } \\
\text { e-mail }\end{array}$} & Jon90 & Limited social life & Craftsman & $\begin{array}{l}\text { Uses Skype and e-mail frequently } \\
\text { with family. }\end{array}$ \\
\hline & Lisa90 & Mostly family & Service worker & $\begin{array}{l}\text { Receives messages and photos } \\
\text { from family. }\end{array}$ \\
\hline & Mary80 & Mostly family & Clerk & $\begin{array}{l}\text { Has started using Skype briefly with } \\
\text { family. }\end{array}$ \\
\hline & Kristian85 & Mostly family & $\begin{array}{l}\text { Graduate } \\
\text { engineer }\end{array}$ & $\begin{array}{l}\text { Has tried Skype. E-mails a lot with } \\
\text { family. Sends and receives photos. }\end{array}$ \\
\hline & Morten75 & Mostly family & $\begin{array}{l}\text { Graduate } \\
\text { engineer }\end{array}$ & $\begin{array}{l}\text { Some use of Skype and e-mail with } \\
\text { his children. }\end{array}$ \\
\hline & Tor60 & Mostly family & Transport & $\begin{array}{l}\text { E-mail to keep in touch with family } \\
\text { and children. They also send } \\
\text { photos. }\end{array}$ \\
\hline & Per65 & Mostly family & $\begin{array}{l}\text { Business } \\
\text { professional }\end{array}$ & $\begin{array}{l}\text { E-mails frequently. Curious on } \\
\text { Facebook, but finds it too } \\
\text { superficial. }\end{array}$ \\
\hline & Johan65 & Family and friends & Transport & $\begin{array}{l}\text { E-mails frequently with friends and } \\
\text { family. }\end{array}$ \\
\hline & Heidi65 & Family and friends & Clerk & $\begin{array}{l}\text { Skypes weekly with children/grand- } \\
\text { children. Interested in Facebook. }\end{array}$ \\
\hline \multirow[t]{6}{*}{ Facebook } & Irene65 & Mostly family & $\begin{array}{l}\text { Ass. } \\
\text { professional }\end{array}$ & $\begin{array}{l}\text { E-mail, Skype and Facebook with } \\
\text { family and re-connected friends. }\end{array}$ \\
\hline & Jenny85 & Mostly family & Gardener & $\begin{array}{l}\text { Facebook to keep in touch with } \\
\text { family. }\end{array}$ \\
\hline & Inger75 & Family and friends & Service worker & $\begin{array}{l}\text { Uses Facebook a lot with family and } \\
\text { friends. }\end{array}$ \\
\hline & Olav60 & Family and friends & Transport & $\begin{array}{l}\text { Some use of Facebook with family } \\
\text { and re-connected friends. }\end{array}$ \\
\hline & Nina65 & Family and friends & Service worker & $\begin{array}{l}\text { Facebook to keep in touch with far } \\
\text { away family. }\end{array}$ \\
\hline & Harald65 & Family and friends & Craftsman & $\begin{array}{l}\text { Uses e-mail, Skype and Facebook } \\
\text { with family and friends. }\end{array}$ \\
\hline
\end{tabular}

Table 2: Overview of whether and how participants have started to use online communication.

Participants who have not started using online communication are not (yet) interested, find it too difficult to learn, or argue they would not have anyone to communicate with online. Ruth95 for example resigned explains that she finds it difficult to use e-mail, and "I'm not any good at writing messages, besides I don't actually have anyone to write to either". Instead Ruth95 and the other participants who have not really started using online communication rely on the phone as their preferred way of keeping in touch with family and friends. Among our participants, non-users tend to be older and express greater learning-difficulties. The phone also remains important for those who have started using online communication. The participants have experienced the widespread 
adoption of landline phones and later mobile phones, and for most of them phone calls and textmessages represent a familiar and valuable way of keeping in touch with family and friends. Given their preference for prioritizing close social ties, phone calls and text-messages are experienced as sufficient means for maintaining relationships, hence confirming continued relevance of previous research (Aronson [1971] 1986; Haddon and Silverstone 1996; Ling 2008) in a communicative culture that has changed significantly over the last 10 years.

Many describe how they almost have regular schedules for phone-calls to close friends and family. Whereas phone-calls and text-messages are valued by most participants, some lament that they do not like to talk on the phone. Others express tensions; they regularly talk on the phone, but find it slightly tedious. Jon90 explains how he talks with his sister every morning, with phone-calls sometimes lasting for an hour: "But it's not as if we talk about important things, it's more like tittletattling." In the follow-up interview, it appears that these daily phone-calls are experienced as slightly too much.

I think it's too much talking. It's an endless repeat. She's alone too. And when you don't experience anything else than what's on the telly, or now with the football world-cup, then... We talk about the same things over and over again, and a lot about our childhood and the old days (Jon90, interview 2).

Jon90 has a limited social life and mainly keeps in touch with his niece and his sister, with occasional visits, phone-calls, Skype and some e-mailing. His doctor has urged him to get out, attend social events and meet people, but he does not want to: "I don't know what stopping me. It's the person I am." For him, the iPad and the means of communication it supports, has value in slightly extending the social connectedness to his niece and sister. Although his life-situation is very different from the more outgoing participants, they share a curiosity into how online communication complement and enrich ways of connecting with close ties.

The perceived and experienced appeal of digital modes of connecting seems related to being able to recognize and relate digital communication to established forms of mediated communication such as phone-calls. Skype is attractive because participants recognize its resemblance to phone-calls and text-messaging with close ties, with the novelty of the webcam being experienced as a welcomed social enrichment. Similarly, e-mail is used to send brief updates and to receive photos. This is particularly the case for participants with close family and friends living geographically far away. Irene65 has had poor physical health for 25 years, and her condition makes it difficult for her to visit and get visits by family members and friends. In the first interview, she describes how her last visit to Sweden was too demanding for her, and how Skype could be a visual bridge to keep in touch with her family instead: 
It would be wonderful to be able to see each other [on Skype]. You get closer to each other when you get to see peoples' faces and the surroundings. I'm tired and exhausted, but my family pushed me and claimed it would be good for me to visit our family-place in Sweden. I was away for a week, and it was a nightmare. Even if I love my family and the place, yes because this place represents my roots. I must say, to see all my relatives on Skype, and they could show me the place. I would like that. (...) There are relatives in line, who want to get in touch, and I want to get in touch, and it'd be really nice to see their faces (Irene65, interview 1).

In interview two and three, as Irene has had a chance to learn more about both Skype and emailing, she explains how this has made her able to re-connect with her family. She receives photos of their children and surroundings, and they now include her in their lives:

You know with these younger people, it's easier for them to sit down in cyberspace than to sit down and write a letter. I've written letters before, but received nothing in return. But now [with email and Skype] I do. In a rather large quantity (Irene 65, interview 2).

For Irene, Skype and e-mail enable a form of communication not possible with regular phone-calls, and it is telling how she emphasizes the visual and mediated presence of family ties. Likewise, for the relatively young and socially outgoing Harald65, Skype and Facebook have now become ordinary means of keeping in touch with friends: "I talk a lot with one mate on Skype. He's spends winters in Spain, and we talk on Skype daily. It's great."

The perceived and experienced value of Facebook. As noted in Table 2, six participants have started to use Facebook. None of them use other SNSs than Facebook. Our findings confirm previous research (Braun 2013; Chung et al. 2010; Gibson et al. 2010; Xie et al. 2012; Lehtinen et al. 2009; Nef et al. 2013) that shows how the participants who have now started to use Facebook experience it as an enriching and complementary way of keeping in touch with friends and family, and to re-connect with old friends. Non-users explain they are not interested in Facebook; are not able to learn to use it; or basically find it a superficial and trivial form of communication. To take one of the more curious non-users, Per65 has registered to Facebook, yet keeps activating and de-activating his account. In the second and third interviews, he explains how he is interested in using Facebook for discussing political and societal issues, though consistently feels discouraged observing the small talk and hollowness of the glossy depictions he finds that others share.

The main contribution of our study to the extant literature is that it shows how the longitudinal, qualitative approach allows for a nuanced and contextual analysis of what makes some older people first recognize, and subsequently experience first-hand, the particular communicative culture of Facebook. This is no easy task for previously digitally excluded, given the lack of pre-digital 
analogues of Facebook. Facebook does not resemble anything they have previously encountered, and represents an unfamiliar communicative culture (see also Lüders and Brandtzæg 2017).

Additionally, admitting our qualitative material cannot be used to generalize beyond the participants, our findings hint at the need to explore associations between offline social ties and the experienced value of Facebook. In technology-acceptance studies of Facebook and SNSs, the perceived social value of SNSs is typically measured with items on whether SNSs are perceived as valuable for keeping in touch with family and friends, and for getting to know new people (Braun 2013; Chung et al. 2010; Lüders and Brandtzæg 2017). Such items pre-suppose either that people aldready have a rich social network to connect with, or that they are interested in getting to know new people. For older people with a limited social life, both premises might align poorly with reality.

Participants who already are content with their social life also use Facebook to re-connect with old friends and family. In the follow-up interview, Olav60 for example describes how he has found an old friend from school-days, and finds it interesting to keep in touch in a less committing way. Irene65, similarly values the opportunity to re-connect with old friends.

I lived in the US for three years. And I got a friend-request from a very close friend I haven't been in touch with since the early 1970s. That was a lot of fun, because we used to be very close. Actually I get [laughs] quite a lot of friend-requests on Facebook. It's like, oh help [laughs]. You know because of my illness. But it's really nice to re-connect with friends you grew up with. It's a lot of fun. My challenge is to limit myself (Irene65, Interview 3).

Irene's primary motivation for using Facebook is to keep in touch with her family, and to easily be able to see the photos they share. For Irene then, Facebook and Skype represent similar social benefits in visually enriching mediated communication with her family. She uses Facebook daily, and has eventually realized she does not need to respond to everything; Facebook is different compared to other forms of mediated communication where actively responding is expected for communication to be meaningful.

Participants who have not started using Facebook typically explain they are not interested in broadcasting every little detail in their life. Conversely, participants who have started using Facebook have realized extensive active participation is not required for Facebook to be socially meaningful for them. They use it more to see what others share.

I use Facebook a lot. I'm curious you know [laughs], and I think Facebook is alright. I use it just to observe. I have children and grand-children, and several old friends from the valley. I don't write anything. You kind of need to learn it first, take one step at a time (Inger75, Interview 2). 
Realizing Facebook can be used even if not actively sharing content may seem trivial, particularly given such passive use is in fact typical among Facebook-users in other age-groups (Brandtzæg 2012). Yet to reiterate, the particular culture of communication on Facebook has few, if any, predigital analogues. For non-users, vicarious impressions and experiences of Facebook do not sufficiently well capture the appeal and particularities of Facebook as something with social relevance and value. The Facebook way of social seems to require first-hand experience over some time in order to make sense. Among the study-participants, the more well-connected older people are intrigued to give Facebook a chance and little-by-little learn to appreciate a less committing form of staying in touch with a larger network of family and friends.

Warm experts. Table 2 suggests that participants who are already well connected with family and/or friends benefit from these relationship when it comes to adoption of new communications technologies. Well-connected participants often talk about their immediate social relations as support-people in the learning-process - pointing to what Bakardjieva (2005) referred to as warm experts. Arne90 explains how his family helps him, because they are interested; Johan65 describes how he can always rely on his son-in-law to assist when in trouble; Morten75 shares how his son has helped him with photos and Skype; and Inger75 talks about how her grand-children eagerly share what they know. In this study we additionally relied on volunteers as regular support-people for the participants. In the last interview with Kristian85, he describes a systematic reliance on both family and volunteers:

Kristian85: I e-mail my children and grand-children. E-mailing is really handy. I also get photos and send photos and add some text. I have these albums now with old photos from the cabin and things I like. I have four or five albums I look through. My son helped me with it. It's not a problem for me because I easily get help by those who visit me. And if I have a problem, I make a note, and then I get help. It's the same with the school-kids [the volunteers]. I have a list with 10-15 points that they help me sort out. And if it's something special, my son can stop by and help me.

Participants with a richer social life hence tend to experience a double benefit: both having people to communicate with online, and having close people acting as warm experts. Volunteer helpers to some extent act as warm experts, yet can only partially compensate for a limited social life:

Ruth95: You know, they [the volunteers] are young and everything goes so quickly. When I ask about something, they do it so quickly. It takes a bit of time for old people. They're very sweet and kind. And I wouldn't have managed on my own. So they have taught us something.

\section{Conclusion}


With ever-present smartphones in the surroundings of the participants, there is a gradual reduction in the opacity of the window to the online world. The always-on culture interferes with social situations, yet at the same time, the online world becomes more familiar and interesting. The window is no longer fully opaque, but includes transparent parts.

Participants who have not started using online communication see value in online access to entertainment, news, and information. But they do not see value in terms of enhanced social connectivity. They explain that for their lives, online communication is irrelevant, un-interesting, too difficult, or, most importantly, they would have no one to contact online. Whereas the first three explanation resonates with the extant literature (see e.g. Braun 2013; Lehtinen et al. 2009; Lüders and Brandtzæg 2017; Nef et al. 2013), the last one has rarely been discussed. This is surprising given the prominence of the "rich get richer" model in research on the social consequences of online communication for other age-groups (Kraut et al. 2002; Valkenburg and Peter 2009).

Among our participants it seems that those who are already well connected also find online communication, including Facebook, more relevant and attractive (see Table 2). As people approach the end of life and increasingly care more about close and meaningful social ties (Carstensen et al. 2003), online communication is appealing if it increases opportunities for interactions with close ones. Older people with less social support offline do not find online communication as relevant for maintaining the few social connections they have. Moreover, unlike younger age-groups (Steinfield et al. 2008), they are less interested in investing in maintaining weak social ties, offline or online.

Older people with richer social networks are in a better position to leverage the social opportunities of online communication. Hence, the "rich get richer" model appears particularly relevant for older citizens - The socially rich get socially richer. Notice that "socially richer" here primarily concerns improved opportunities to maintain close social ties, as opposed to opportunities for re-connecting and thus expanding social networks that young people find attractive. We encourage future research to study this finding with larger samples and quantitative data.

It is also likely that the opportunity to connect with others differs between people in their 60 s and 70 s compared to people in their 80 s and 90 s. Even those who have had a rich and extensive social life will to a large extent experience the loss of friends and family when they reach the latter years of their lives. The older participants do to a larger extent settle with their new life-situation as long as they still have a few important relationships left. Moreover, even if tablets represent a lower learning-threshold, the oldest participants tend to express greater learning-difficulties.

The majority of the participants have started using some form of online communication, to smaller and larger extent. For these participants, online modes of communicating extend and enrich ways of 
staying in touch, in a less socially demanding way, and to a large degree fit the preferences the older people have for maintaining the social contacts important for them. E-mailing and Skyping come across as more familiar ways of communicating, resembling text-messages, letters, and phone calls. E-mailing and Skyping enable symmetrical dialogue, compared to the stranger culture of communication on Facebook, where content is broadcasted to a heterogeneous group of contacts and friends. Yet those who start using Facebook and who have people to connect with eventually learn to appreciate the peculiarities of the less committing Facebook way of social, where response and sharing of content is not a requirement for keeping in touch.

Facebook is no longer only a social platform for communicating with friends, but increasingly a platform for the dissemination of editorial content, entertainment, political and other communications. Facebook hence has potential use-value beyond connecting with family and friends. Yet our participants still have limited awareness of the full scope of Facebook. Their interest in Facebook remains limited to keeping in touch with and re-connecting with friends and family, and as such resembles how most of us first encountered Facebook.

The experiences of participants who have started using online communication by and large suggest that older people may indeed value the opportunities for extending the social sphere of their lives, with online communication enriching ways of keeping in touch with family and friends, and for reconnecting with old friends. Yet these are conditioned experiences, meaning the perceived and realized social potential of online communication can only be understood when antecedents influencing the social quality of life of older people, offline and subsequently online, are taken into account.

\section{Acknowledgements}

This work was supported by Regionale Forskningsfond - Hovedstaden grant 217609/97231.

The authors would like to thank Anne Moen, Elisabeth $\varnothing$ stensen, Tone $\varnothing$ derud and Ida Maria Haugstveit for their participation in conducting interviews.

\section{References}


Ala-Mutka, K., N. Malanowski, Y. Punie, and M. Cabrera. 2008. Active Ageing and the Potential of ICT for Learning. Seville, Spain: European Commission, Joint Research Centre, Institute of Prospective Technological Studies.

Aronson, S. H. [1971] 1986. The Sociology of the Telephone. In Inter/Media: Interpersonal Communication in a Media World, ed. G. Gumpert and R. Cathcart, 300-310. New York: Oxford University Press.

Ashida, S., and C. A. Heaney. 2008. Differential Associations of Social Support and Social Connectedness With Structural Features of Social Networks and the Health Status of Older Adults. Journal of Aging and Health 20(7):872-893.

Bakardjieva, M. 2005. Internet Society: The Internet in Everyday Life. London: Sage.

Bowling, A. 2009. Perceptions of active ageing in Britain: divergences between minority ethnic and whole population samples. Age and Ageing 38(6):703-710.

Brandtzæg, P. B. 2012. Social Networking Sites: Their Users and Social Implications - A Longitudinal Study. Journal of Computer-Mediated Communication 17(4):467-488.

Braun, M. T. 2013. Obstacles to social networking website use among older adults. Computers in Human Behavior 29(3):673-680.

Burke, M., R. Kraut, and C. Marlow. 2011. Social capital on facebook: differentiating uses and users. In Proceedings of the SIGCHI Conference on Human Factors in Computing Systems, pp. 571580. New York: ACM.

Caprani, N., O'Connor, N.E. and C. Gurrin. 2012. Touch screens for the older user. In Assistive Technologies, ed. F. A. Cheein, 95-118. Rijeka, Croatia: In Tech.

Carstensen, L., H. Fung, and S. Charles. 2003. Socioemotional Selectivity Theory and the Regulation of Emotion in the Second Half of Life. Motivation and Emotion 27(2):103-123.

Cathcart, R. S., and G. Gumpert. 1986. Mediated Interpersonal Communication: Toward a New Typology. In Inter/Media: Interpersonal Communication in a Media World, ed. G. Gumpert and R. S. Cathcart, 26-40. New York: Oxford University Press.

Chung, J. E., N. Park, H. Wang, J. Fulk, and M. McLaughlin. 2010. Age differences in perceptions of online community participation among non-users: An extension of the Technology Acceptance Model. Computers in Human Behavior 26 (6):1674-1684.

Cornwell, E. Y. and L. J. Waite. 2009. Social Disconnectedness, Perceived Isolation, and Health among Older Adults. Journal of Health and Social Behavior 50(1):31-48.

Cornwell, B. 2011. Independence Through Social Networks: Bridging Potential Among Older Women and Men. The Journals of Gerontology Series B: Psychological Sciences and Social Sciences 66B(6):782-794.

Coyle, C. E. and E. Dugan. 2012. Social isolation, loneliness and health among older adults. Journal of aging and health 24(8): 1346-1363. 
Duggan, M. 2015. Mobile Messaging and Social Media - 2015. Washington, DC: Pew Research Center.

Dykstra, P. A. 2009. Older adult loneliness: myths and realities. European Journal of Ageing 6(2):91100.

Ellison, N. B., J. Vitak, R. Gray, and C. Lampe. 2014. Cultivating Social Resources on Social Network Sites: Facebook Relationship Maintenance Behaviors and Their Role in Social Capital Processes. Journal of Computer-Mediated Communication 19(4):855-870.

English, T., and L. Carstensen. 2014. Selective narrowing of social networks across adulthood is associated with improved emotional experience in daily life. International Journal of Behavioral Development 38(2):195-202.

Farquhar, M. 1995. Elderly people's definitions of quality of life. Social Science \& Medicine 41(10):1439-1446.

Findlater, L., J. E. Froehlich, K. Fattal, J. O. Wobbrock, and T. Dastyar. 2013. Age-related differences in performance with touchscreens compared to traditional mouse input. In Proceedings of the SIGCHI Conference on Human Factors in Computing Systems, 343-346. New York: ACM.

Fischer, C. S. 1992. America calling. Berkeley, CA: University of California Press.

Garattini, C., J. Wherton, and D. Prendergast. 2012. Linking the lonely: an exploration of a communication technology designed to support social interaction among older adults. Universal Access in the Information Society 11(2):211-222.

Gibson, L., W. Moncur, P. Forbes, J. Arnott, C. Martin, and A. S. Bhachu. 2010. Designing social networking sites for older adults. In Proceedings of the 24th BCS Interaction Specialist Group Conference. Dundee, UK: British Computer Society.

Haddon, L. and R. Silverstone. 1996. Information and Communication Technologies and the Young Elderly (SPRU CICT Report Series No. 13). Brighton, UK: Science Policy Research Unit, University of Sussex.

Hakkarainen, P. 2012. "No good for shovelling snow and carrying firewood": Social representations of computers and the internet by elderly Finnish non-users. New Media \& Society 14(7):1198-1215.

Hauge, S., and M. Kirkevold. 2012. Variations in older persons' descriptions of the burden of loneliness. Scandinavian journal of caring sciences 26(3):553-560.

Haythornthwaite, C. A. 2002. Strong, Weak, and Latent Ties and the Impact of New Media. The Information Society 18(5):385-401.

Honigh-de Vlaming, R., A. Haveman-Nies, I. Bos-Oude Groeniger, L. de Groot, and P. van 't Veer. 2014. Determinants of Trends in Loneliness Among Dutch Older People Over the Period 2005-2010. Journal of Aging and Health 26(3):422-440. 
Kraut, R., Kiesler, S., Boneva, B., Cummings, J., Helgeson, V., and A. Crawford. 2002. Internet Paradox Revisited. Journal of social issues 58(1):49-74.

Lehtinen, V. J. Näsänen and R. Sarvas. 2009. "A little silly and empty-headed": older adults' understandings of social networking sites. In Proceedings of the 23rd British $\mathrm{HCl}$ Group Annual Conference on People and Computers: Celebrating People and Technology. pp. 45-54. Cambridge, UK: British Computer Society.

Lindley, S. E., R. Harper and A. Sellen. 2008. Designing for Elders: Exploring the Complexity of Relationships in Later Life. In Proceedings of the 22nd annual conference of the British $\mathrm{HCl}$ Group Annual Conference on People and Computers, Creativity, Interaction (Volume 1), pp. 77-86. Cambridge, UK: British Computer Society.

Ling, R. 2008. Should We Be Concerned That the Elderly Don't Text? The Information Society 24(5): 334-341.

Liu, B. S., and K. S. Rook. 2013. Emotional and social loneliness in later life: Associations with positive versus negative social exchanges. Journal of Social and Personal Relationships 30(6):813-832.

Lüders, M. and P.B. Brandtzæg. 2017. "My children tell me it's so simple”: A mixed-methods approach to understand older non-users' perceptions of Social Networking Sites. New Media \& Society 19 (2): 181-198.

Nef, T., R. Ganea, R. M. Müri and U. P. Mosimann. 2013. Social networking sites and older users - a systematic review. International Psychogeriatrics 25(7):1041-53.

Ofcom. 2015. Adults' media use and attitudes. Ofcom report 2015. Retrieved 19 December 2015, (http://stakeholders.ofcom.org.uk/market-data-research/other/researchpublications/adults/media-lit-10years/).

Orimo, H., Ito, H. Suzuki, T., Araki, A., Hosoi, T., and M. Sawabe. 2006. Reviewing the definition of 'elderly'. Geriatrics \& Gerontology International 6(3): 149-158.

Peters, J. D. 1999. Speaking into the air: A History of the Idea of Communication. Chicago: University of Chicago Press.

Savikko, N., P. Routasalo, R. S. Tilvis, T. E. Strandberg and K. H. Pitkälä. 2005. Predictors and subjective causes of loneliness in an aged population. Archives of Gerontology and Geriatrics 41(3):223-233.

Selwyn, N. 2004. The information aged: A qualitative study of older adults' use of information and communications technology. Journal of Aging Studies 18(4):369-384.

Steinfield, C., Ellison, N. B., and C. Lampe. 2008. Social capital, self-esteem, and use of online social network sites: A longitudinal analysis. Journal of Applied Developmental Psychology 29(6):434-445.

Turkle, S. 2011. Alone Together: Why We Expect More from Technology and Less from Each Other. New York: Basic Books. 
Turkle, S. 2008. Always-on/always-on-you: The tethered self. In Handbook of Mobile Communication Studies, ed. J. E. Katz, 121-137. Cambridge, MA: MIT Press.

Utz, R. L., D. Carr, R. Nesse, and C. B. Wortman. 2002. The Effect of Widowhood on Older Adults' Social Participation: An Evaluation of Activity, Disengagement, and Continuity Theories. The Gerontologist 42(4):522-533.

Vaage, O. F. 2015. Norsk mediebarometer 2014. In Statistiske analyser. Oslo: Statistisk sentralbyrå.

Valkenburg, P. M., and J. Peter. 2009. Social consequences of the internet for adolescents a decade of research. Current Directions in Psychological Science 18(1):1-5.

Walker, A. and H. Mollenkopf. 2007. International and multidisciplinary perspectives on quality of life in old age. In Quality of life in old age international and multi-disciplinary perspectives, ed. H. Mollenkopf and A. Walker, 3-13. Dordrecht, the Netherlands: Springer.

WHO. 2002. Active Ageing: A Policy Framework. World Health Organisation 2002. Retrieved onNovember 10 from http://whqlibdoc.who.int/hq/2002/WHO_NMH_NPH_02.8.pdf.

Xie, B., I. Watkins, J. Golbeck, and M. Huang. 2012. Understanding and Changing Older Adults' Perceptions and Learning of Social Media. Educational Gerontology 38(4):282-296. 